\title{
Network centrality and student self-efficacy in an interactive introductory physics environment
}

\author{
Remy Dou* and Eric Brewe*† \\ *Department of Teaching and Learning, Florida International University, $11200 \mathrm{SW} 8^{\text {th }}$ ST, Miami, Fl 33199 \\ † Department of Physics, Florida International University, 11200 SW ${ }^{\text {th }}$ ST, Miami, Fl 33199
}

\begin{abstract}
Collaborative learning environments in undergraduate introductory physics courses, such as those promoted by University Modeling Instruction (UMI), influence both student performance and behavioral constructs. Of these constructs, self-efficacy has the power to predict student performance and persistence in the major. Our study examines a plausible mechanism by which self-efficacy may be influenced in these collaborative courses, particularly as it relates to two sources of self-efficacy: vicarious learning and verbal persuasion. We found that social network analysis-based centrality measures are positively correlated with self-efficacy scores on the Sources of Self-Efficacy in Science Courses-Physics (SOSESC-P) for students in either traditional lecture or UMI introductory physics courses. Moreover, centrality scores - calculated as either degree centrality or undirected PageRank centrality - correlate positively with scores on the vicarious learning and verbal persuasion subsection of the SOSESC-P. This suggests that collaborative, inquiry-based learning environments may promote higher student self-efficacy.
\end{abstract}

Keywords: Self-efficacy, social network analysis, centrality, physics-oriented social networks PACS: 01.40.Di, 01.40.Fk, 01.40.gb

\section{SOCIAL INTERACTIONS IN THE PHYSICS CLASSROOM}

Undergraduate introductory physics courses have received a great deal of attention in education research, some of which focuses on the development and evaluation of course designs that incorporate reformed teaching curricula. These reformed curricula, including the Investigative Science Learning Environments (ISLE) and University Modeling Instruction (UMI), often incorporate structures that promote collaborative learning through student interactions [1,2]. Although collaborative learning environments promote more positive student outcomes and attitudes in comparison to lecture courses, the mechanisms for these results are not always clear [3]. This paper contributes to that discussion by describing a pilot analysis examining the role of student centrality in a physics-oriented social network and its correlation with self-efficacy building activities in a classroom.

\section{Roles of Social Networks in School}

A school environment is social by nature. Students interact with peers and faculty in a variety of ways, often forming dynamic networks or communities. These networks exist both in and out of the classroom. Researchers in science education have described the value of examining social networks in $\mathrm{K}-12$ and undergraduate education, highlighting its ability to help explain how classroom interactions impact student behavior [4]. More specifically, this approach has led to greater insights in undergraduate physics education, such as an initial understanding of how student positions in a social network can help predict grades in future courses and a clearer description of informal networks in a physics learning center $[5,6]$.

Students in our study formed several physicsoriented communities with a variety of individuals. Each student in this analysis is represented as a node in a network that combines self-reported interactions of participants attending either lecture or UMI introductory physics courses. Their interactions with others are represented by edges connecting one node (i.e. person) to another. Node centrality is a measure of a node's role in the network, which can be defined as a factor of both the number of nodes with whom that person is connected (i.e. degree centrality) or the popularity of the nodes with whom that person is connected (i.e. PageRank centrality). The language of social network analysis has been described with more nuance in previously cited documents [4-6].

\section{The Social Nature Of Self-Efficacy}

Bandura describes four commonly accepted sources of self-efficacy (i.e. a person's expectation about his or her ability to accomplish a certain task) [7]. Of the four sources-mastery experiences, vicarious learning, verbal persuasion, and physiological mechanismstwo exist primarily in social settings: vicarious learning (VL) and verbal persuasion (VP). VL 
experiences occur when a person makes personal comparisons when observing the success or failure of someone whom that person perceives as similar. VP experiences involve receiving feedback from other individuals [8]. By definition, these behavioral constructs-VL and $\mathrm{VP}$ - generally require social interactions, though not necessarily synchronous as in the case of video or text.

High scores on self-efficacy measures have been positively correlated with a variety of student outcomes. These include academic success in math and science [9], perseverance on tasks [7], and career persistence [10]. Because of the consequential role of self-efficacy, attention should be paid to classroom structures that influence students' self-efficacy. In an attempt to glance behind the mechanistic veil, we look at the correlation between centrality in a physicsoriented social network and the types of self-efficacy building experiences students encounter.

\section{CONTEXT OF STUDY}

Our data collection took place during the 2009 fall semester at Florida International University (FIU) - a Hispanic Serving Institution located in Miami, F1. At the time, approximately $64 \%$ of students at FIU were Hispanic, followed by a much smaller distribution of White and African-American students [11]. Over the past decade, the physics education research (PER) group at FIU has explored a variety of research topics that focus on the impact of UMI in undergraduate introductory physics. UMI courses are structured to elicit peer interactions, having students work in groups and later share results as part of a larger, class-wide discussion [12]. This component of UMI instruction lends itself to more active, participatory learning, which contrasts with the traditionally passive design of physics lecture courses that cater to a greater number of students.

In addition to exhibiting higher gains in student FCI scores when compared to those in lecture courses [12], UMI courses do not negatively impact students' selfefficacy, as do traditional courses [13]. This same analysis showed that female students who took a preand post- version of the Sources of Self-Efficacy in Science Courses-Physics (SOSESC-P) survey showed significant gains in the verbal persuasion subsection. Considering the inherently social characteristic of the VL and VP sources of selfefficacy, we hypothesized that students with high degree centrality and undirected PageRank centrality would be more likely to report having experienced self-efficacy building activities, particularly those activities related to vicarious learning and verbal persuasion.

\section{METHODS}

The SOSESC-P was administered online at the beginning and end of the fall 2009 semester. This 33item, five-point Likert-scale survey was sent as an email to every student registered in an UMI introductory physics course (i.e. Physics 2048) $\left(\mathrm{N}_{\mathrm{UMI}}=80\right)$ or the equivalent lecture section of the course $\left(\mathrm{N}_{\text {Lecture }}=329\right)$. The SOSESC-P is worded in such a way so as to gauge the type and impact of self-efficacy building activities as a reliable proxy for self-efficacy with a reliability coefficient of .94 [14]. As part of the design of this preliminary data examination, only the students who submitted a social network survey and a complete postSOSESC-P were included in the statistical analysis $\left(\mathrm{N}_{\mathrm{UMI}}=49, \mathrm{~N}_{\text {Lecture }}=24\right)$.

To measure the position of individual students within the social network of students taking Physics I during that semester, instructors administered a twoquestion paper survey at the beginning and end of each section of the course. The first question asked students to list with whom they worked to learn physics. The second question asked students whether they spent time in the Physics Learning Center. The second question was not considered in this analysis, and only the post social network survey was included as a measure of student centrality after participants had an entire semester to form working relationships with peers. All students and non-students mentioned in the social network survey were included in the sociogram $(\mathrm{N}=291)$ for a more accurate representation of the network (see Fig. 1).

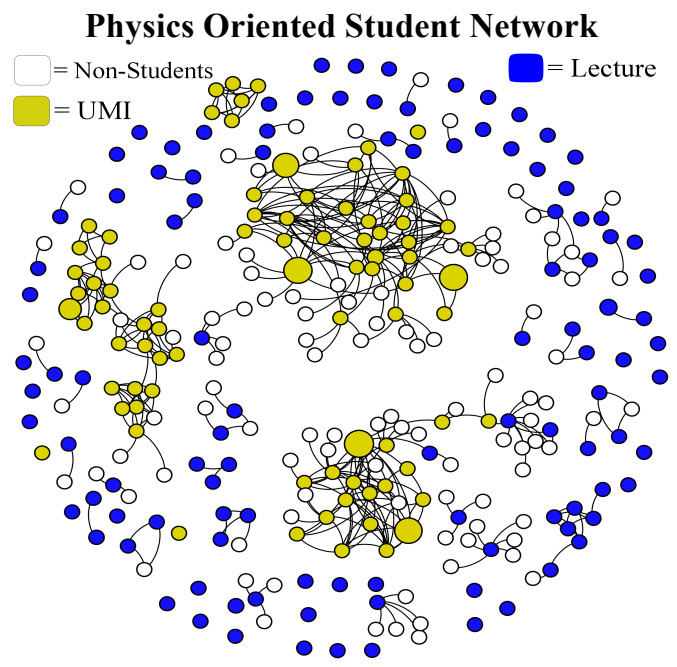

FIGURE 1. Sociogram showing students in the network. Labeled nodes specify the course type of those whose data was included in the study.

Using this survey an adjacency matrix was created to record whom each student reported working with. 
Because of the open-ended nature of the survey, instructors and learning assistants were sometimes mentioned. Additionally, instances occurred where a student in one section of Physics I reported having worked with a student in another section of the same course during the same semester. On occasion, students listed having worked with family members or other non-students. Because each listed person affects the centrality score of individuals in the network, a comprehensive approach was taken where every person listed was included in the final adjacency matrix.

\section{RESULTS}

The scoring of the SOSESC-P survey, social network analysis (SNA), and statistical tests were done using $\mathrm{R}$ and the statnet package $[15,16]$. UMI students were grouped together. An undirected variation of PageRank calculation was used to gauge Lecture and PageRank centrality. We ran Pearson correlations between variables. In order to account for the dependency in the data, we used permutation correlation tests of significance to calculate $\mathrm{p}$-values.

Each measure of centrality (i.e. degree and PageRank) correlated positively with student total score on the post-SOSESC-P survey (Degree centrality: $\mathrm{R}^{2}=.14, \mathrm{p}<.001$; PageRank centrality: $\mathrm{R}^{2}$ $=.07, \mathrm{p}<.05)($ see Fig. 2,3). Questions on the VL subsection of the SOSESC-P included items such as, "Watching other students in class made me think that I could not succeed in physics" and "I could relate to many classmates who were involved and attentive in class." Each measure of centrality also correlated significantly with the VL subsection of the survey (Degree centrality: $\mathrm{R}^{2}=.14, \mathrm{p} \approx 0$; PageRank centrality: $\mathrm{R}^{2}=.06, \mathrm{p}<.05$ ). Relatedly, questions on the VP section of the survey included, "My peers in this course encouraged me that I had the ability to do well on class projects/assignments." Scores on this section of the survey correlated with measures of centrality (Degree centrality: $\mathrm{R}^{2}=.19, \mathrm{p} \approx 0$; PageRank centrality: $\left.\mathrm{R}^{2}=.12, \mathrm{p}<.05\right)($ see Table 1$)$.

TABLE 1. Correlation coefficients $(r)$ between centrality variables and total score on SOSESC-P.

\begin{tabular}{|l|c|c|c|}
\hline Variables & $\begin{array}{c}\text { Total score } \\
\text { on } \\
\text { SOSESC-P }\end{array}$ & $\begin{array}{c}\text { Score on VL } \\
\text { subsection of } \\
\text { SOSESC-P }\end{array}$ & $\begin{array}{c}\text { Score on VP } \\
\text { subsection of } \\
\text { SOSESC-P }\end{array}$ \\
\hline $\begin{array}{l}\text { Degree } \\
\text { centrality }\end{array}$ & $.38^{* * *}$ & $.38^{* * *}$ & $.44^{* * *}$ \\
\hline $\begin{array}{l}\text { PageRank } \\
\text { centrality }\end{array}$ & $.26^{*}$ & $.25 *$ & $.34 * *$ \\
\hline
\end{tabular}

$* \mathrm{p}<.05 * * \mathrm{p}<.01 * * * \mathrm{p}<.001$

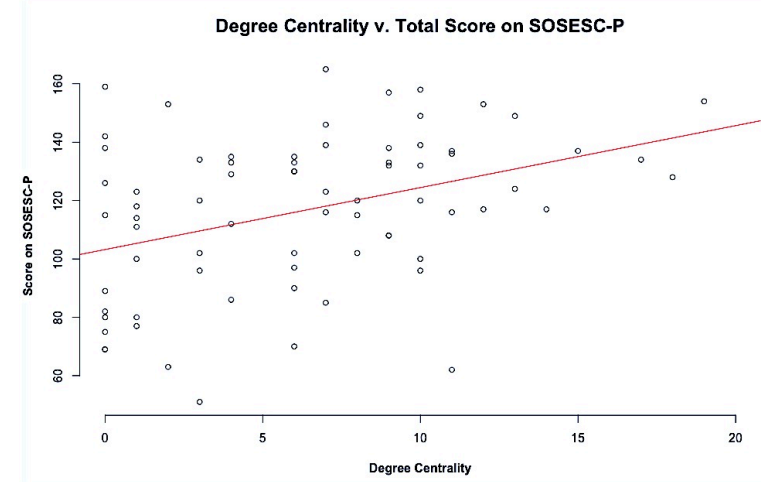

FIGURE 2. Scatterplot showing a linear correlation between degree centrality and total score on the SOSESC-P.

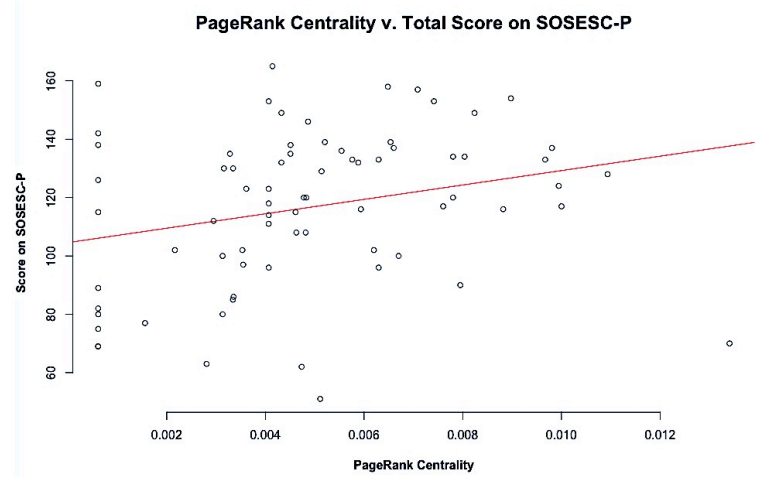

FIGURE 3. Scatterplot showing a linear correlation between PageRank centrality and total score on the SOSESC-P.

\section{DISCUSSION}

Here we used SNA to quantify the social interactions of students in both lecture and UMI sections of Physics I. Considering the social nature of vicarious learning and verbal persuasion, we suspected that students who have more social experiences in relation to physics assignments would also report more physics self-efficacy building experiences. The reverse may be true as well, but in general, Bandura's selfefficacy framework implies that the experience in question precedes changes in self-efficacy [7]. Previous research suggests the social interactions in an UMI physics classroom seem to offer more selfefficacy building opportunities and more dense social networks $[17,18]$. This preliminary analysis suggests that students who work with many other people on physics problems, as measured by degree centrality, are more likely to report having had more self-efficacy building experiences. Similarly, the measure of Pagerank centrality posits that a person's connectedness to other well-connected students correlates to reporting higher number of self-efficacy building experiences, which may be a result of having access to other social cliques. These correlations held 
true when the data was disaggregated by the VL and VP subsection of the SOSESC-P.

We should keep in mind the limitations of this analysis. There was a significant amount of missing data because only students who both completed the SOSESC-P and the social network survey at the end of the semester were included in the study, which increases selection bias where students with high physics self-efficacy may be more willing to complete a survey that positively reinforces their identity. Furthermore, the social network survey design merits a second iteration. The survey posited ten lines where students could write in who they worked with on physics problems. This wording may pressure students to name more or fewer students than they consider salient. Moreover, the survey did not limit students to name only other students, which means that there is a possibility that the self-efficacy scores may result from interactions with learning assistants, instructors, or individuals outside of class. This particular social network survey did not take into account the dynamics of collaborations, whose participants may change throughout the course of a semester, meaning students may have forgotten who they worked with earlier in the semester.

This preliminary analysis of our data not only provides some evidence that collaborative learning classroom curricula designs, such as UMI, positively impact student self-efficacy due to the more socially connected nature of UMI students versus lecture students (see Figure 1), but also sheds light on potential mechanism by which they do so, particularly with regard to the VL and VP sources of self-efficacy. We support this by describing a significant correlation between centrality (i.e. position in a social network) and VL and VP scores on the SOSESC-P of students at FIU. This also aligns with our understanding of the how the four sources of self-efficacy influence overall self-efficacy $[7,8]$. We chose not to use an instrument that measures student overall self-efficacy directly because of the limitations of those instruments to pinpoint which portion of a person's self-efficacy was a result of a VL or VP experience.

Departments looking to both improve student cognitive understanding of physics and positively influence their self-efficacy should consider adopting more collaborative, inquiry-based approaches to physics learning, such as UMI. Considering the careerrelated research on self-efficacy [10], this may play an important role in improving overall student retention and persistence as physics majors. Future research at FIU will seek to take more accurate measures of student social networks. Additionally, further analysis should illuminate whether positive correlations between centrality and self-efficacy hold true when the data is disaggregated by gender, ethnicity, and interactions of these variables.

\section{Acknowledgments}

We would like to thank Dr. Vashti Sawtelle for her management of the data collection and other important contributions to this project. Similarly, we would like to thank the members of the PER community at FIU. This research was supported by NSF grant \#0802184.

\section{References}

1. E. Etkina and A. Van Heuvelen, Investigative Science Learning Environment - A Science Process Approach to Learning Physics (Washington, DC, 2007), pp. 1-48.

2. I.A. Halloun and D. Hestenes, Am. J. Phys. 55, 455 (1987).

3. National Research Council, Disipline-Based Education Research: Understanding and Improving Learning in Undergraduate Science and Engineering (Washington, DC, 2012).

4. D.Z. Grunspan, B.L. Wiggins, and S.M. Goodreau, Cell Biol. Educ. 13, 167 (2014).

5. J. Bruun and E. Brewe, Phys. Rev. Spec. Top. - Phys. Educ. Res. 9, 020109 (2013).

6. E. Brewe, L. Kramer, and V. Sawtelle, Phys. Rev. Spec. Top. - Phys. Educ. Res. 8, 010101 (2012).

7. A. Bandura, Psychol. Rev. 84, 191 (1977).

8. J. a. Chen and E.L. Usher, Learn. Individ. Differ. 24, 11 (2013).

9. K.D. Multon, S.D. Brown, and R.W. Lent, J. Couns. Psychol. 38, 30 (1991).

10. R.W. Lent, S.D. Brown, and G. Hackett, J. Vocat. Behav. 45, 79 (1994).

11. Florida International University, Common Data Set 20092010, WWW Document, (http:// http://opir.fiu.edu/CDS/CDS2009.pdf).

12. E. Brewe, V. Sawtelle, L.H. Kramer, G.E. O'Brien, I. Rodriguez, and P. Pamelá, Phys. Rev. Spec. Top. - Phys. Educ. Res. 6, 010106 (2010).

13. V. Sawtelle, E. Brewe, L.H. Kramer, C. Singh, M. Sabella, and S. Rebello, in 2010 Phys. Educ. Res. Conf. (American Institute of Physics, 2010), pp. 289-292.

14. H. Fencl and K. Scheel, J. Coll. Sci. Teach. 35, 20 (2005).

15. R Core Team (2013). R: A language and environment for statistical computing. $\mathrm{R}$ Foundation for Statistical Computing.

16. Handcock M., Hunter D., Butts C., Goodreau S., Krivitsky P., Bender-deMoll S. and Morris M. (2014). statnet: Software tools for the Statistical Analysis of Network Data. The Statnet Project.

17. V. Sawtelle, E. Brewe, R.M. Goertzen, L.H. Kramer, N.S. Rebello, P. V. Engelhardt, and C. Singh, in 2011 Phys. Educ. Res. Conf. (American Institute of Physics, 2012), pp. 339-342.

18. E. Brewe, L. Kramer, and G. O'Brien, Changing participation through formation of student learning communities, AIP Conf. Proc. 1289, 85 (2010). 